\title{
DESAFIOS E PERSPECTIVAS PARA EDUCAÇÃO MUSEAL
}

\author{
Jezulino Lucio Mendes Braga'
}

\section{RESUMO}

Este texto apresenta desafios para a educação museal, propondo alguns caminhos para que os museus possam ampliar o atendimento às escolas. Afirma a importância da educação como uma das funções sociais do museu, tomando como referência as discussões da década de 50 e da Mesa de Santiago do Chile de 1972, evento que lançou as bases do que chamamos Nova Museologia. Apresenta também, os documentos preliminares e cartas de compromisso do PNEM (Programa Nacional de Educação Museal), diretrizes recentes para a construção de uma política pública de educação e Museus no Brasil. Discute como a exposição pode ser um elemento para inquirições, problematizações a partir de programas e projetos dos setores educativos. Partimos da premissa de que os museus são espaços para formação sensível e neles, professores, estudantes e educadores de museu partilham concepções de mundo e ressignificam suas posições éticas, estéticas e políticas.

\section{PALAVRAS-CHAVE}

Educação-Museus-Políticas públicas

\begin{abstract}
This article presents challenges for museal education, proposing a number of ways to make possible to museums to expand the service they provide to schools.

Taking as reference the discussions of the 50's and those of the 'Round Table on the Development and the Role of Museums in the Contemporary World' (Santiago, Chile, 1972), an event that laid the foundation of what we call New Museology, the present work states the importance of education as one of the social functions of the museum.

It also presents the preliminary documents and the letters of commitment from PNEM (National Program for museum education), recent guidelines for the construction of a public policy of education and museums in Brazil. Based on programs and projects of the educational sector, this text discusses yet how the exhibition can be an element to inquests and problematization. We started from the premise that the museums are spaces for sensitive training, and that in them, teachers, students and museum educators share worldviews and resignify their ethical, aesthetic and political positions.
\end{abstract}

\section{KEYWORDS}

Education, Museums, and Public Policies

\footnotetext{
' Doutor em Educação pela Universidade Federal de Minas Gerais. Coordenador do Curso de Museologia da Escola de Ciência da Informação/UFMG.
} 


\section{Introdução}

Esse texto reflete sobre os desafios para uma educação museal e propõe caminhos para que os museus contemporâneos possam assumir a função educativa ampliando o atendimento às escolas com projetos e programas específicos como a produção de materiais didáticos, encontro com professores e visitas mediadas.

Partimos da constatação de que a museologia contemporânea propõe um modelo de museu argumentativo que propicia a reflexão sobre a narrativa e que possibilita deslocamentos em nossa forma de pensar e agir. Essa forma de ver o museu foi chamada de museu fórum, onde questões inquietantes emergem das narrativas propostas com as coleções dessas instituições. A noção de um museu que participasse amplamente das formas culturais, sociais e econômicas foi um dos desdobramentos da Mesa Redonda de Santiago do Chile, realizada em 1972, que lançou as bases do que hoje é chamado de Nova Museologia (BITTENCOURT, 2008, p. 37).

O documento de Santiago indicou a necessidade de setores educativos nos museus para mediação com escolas e outros programas para dinamização do acervo e educação integral do homem. Esse documento veio confirmar discussões que já estavam sendo feitas desde a década de 1950, como a realização do seminário A função Educativa dos Museus, promovida pela UNESCO, no Rio de Janeiro, em 1958.

Após a realização desse seminário, o então presidente do ICOM, Georges-Heri Riviére, elaborou diagnóstico em que apontou, entre outras coisas, a crescente importância da educação nos museus e, inclusive, defendeu a elaboração de exposições que fossem de assimilação mais "fácil" para os espectadores, - que chamou de apresentação "ecológica" das narrativas museais (SCHEINNER, 20 I 2, p 23).

Nesse sentido, a Mesa de Santiago não é o marco zero para as discussões da educação museal. No entanto, dada a sua importância entre os museólogos, nunca é demais lembrar os acordos feitos naquele encontro e entre eles a necessidade de que os museus assumissem seu papel na educação integral do homem.

No Brasil, na década de 50 foi realizado um seminário na cidade do Rio de Janeiro promovido pelo ICOM (Conselho Internacional de Museus) no qual foi debatida a função educativa dos museus, gerando vários documentos que antecedem o movimento para criação de um Programa Nacional de Educação Museal dentro do IBRAM. O PNEM, como é conhecido, teve suas bases lançadas na cidade de Petropólis em 2010 e posteriormente a discussão ampliada aconteceu por meio de uma plataforma virtual lançada no dia 30 de outubro de $2012 .{ }^{2}$

Ao assumir seu papel educativo, os museus marcam sua especificidade e ampliam ações que fortalecem o uso educativo de suas exposições; propõe relações com a comunidade e com as escolas, dinamizando e publicizando suas exposições.; e rompem com a visão de uma caixa monumento que encapsula a memória em objetos e legendas, sem se preocupar com as inquirições próprias do social vivido.

\footnotetext{
2 É importante lembrar que as ações educativas nos museus acontecem desde a criação dos primeiros museus no Brasil. Não podemos definir um marco zero para educação museal. Entretanto, existem algumas iniciativas de forma mais sistematizadas que ocorrem na primeira metade do século XX como Serviço de Assistência ao Ensino no Museu Nacional e as ações educativas do Museu Histórico Nacional.
} 


\section{Sobre Museus e a Educação}

Os museus são cada vez mais procurados por professores, que ampliam suas estratégias didáticas para ensinar os conteúdos escolares. Alguns museus se equipam para receber essa demanda criando setores educativos com equipes para atender aos professores e estudantes e elaboram materiais didáticos que servem de suporte para uso pedagógico dos museus.

De acordo com Francisco Régis Lopes Ramos, um dos grandes desafios colocados ao museu na atualidade é a promoção de atividades educativas e uma vez que o museu reconheça este desafio e se adeque à demanda vinda das escolas, as exposições tornam-se mais lúdicas e provocativas (RAMOS, 2004). Para Dominguez, Estepa e Cuenca, "El museo, universo figurado y cargado de significados debe convertirse en un lugar atrayente, motivador, vivo y dinâmico, que sugiera interrogantes ao visitante, ya sean alumnos o publico adulto (DOMINGUEZ, ESTEPA \& CUENCA, 1999, p 20) .

Nessa perspectiva, os museus incluem atividades educativas como uma política interna tão importante como a aquisição de coleções, preservação, montagens de exposições, pesquisa, entre outras funções dessas instituições. É preciso ficar claro que os museus são instituições culturais e promovem a educação pela via da cultura, proporcionando o encantamento, entretenimento, a provocação e o diálogo. $O$ museu estabelece relações com as escolas, mas os códigos de uma instituição e da outra são diferentes.

Margaret Lopes defende a desescolarização dos museus, uma vez que essas instituições situam-se no campo da educação não escolar na qual, "mediante uma grande diversidade de experiências, que relacionam práticas educativas e comunicação social, buscam novas alternativas para seu papel educacional." (LOPES, I99I, p. 443) Segundo a autora o movimento escolanovista levou os métodos e finalidades do ensino escolar para os museus. Para ela a tentativa dos museus de manter um público cativo faz com que organizem cada vez mais seus setores educativos em função da escola.

Nos museus que possuem setores educativos, apesar de grandes avanços ainda existem muitos limites nas atividades que estão sendo desenvolvidas.Ainda permanecem nas chamadas visitas educativas uma lógica transmissiva, a ilusão da visita total e discursos que muitas vezes contradizem o que vem sendo produzido pelas pesquisas acadêmicas. Há especificidades no museu, uma vez que:

El museo es um lugar apto para el aprendizaje (...)pero ofrece algunas limitaciones que los profesores deben conocer. Los museos sintetizan em un reducido espacio uma dilatada cronologia que se perde, com frecuencia, em las remotas fronteras de miles de años, culturas y diversos hitos de la evolución de la humanidad. La comprensión resulta, a veces, de difícil aprehensión para el visitante, por lo que siempre em cualquier tipo de exposición, temporal o permanente, se manifiesta una dependencia informativa del objeto respecto al mensaje que se quiere transmitir. $A$ estas limitaciones se añade que, normalmente, los objetos del museo, alejados y preservados muchos de ellos em vitrinas, aparecen totalmente desconectados y descontextualizados del médio del cual proceden, perdendo su cualidad vital y explicativa dentro de um ámbito más amplio em el que, de manera interrelacionada, se producen las múltiples manifestaciones de la vida del hombre (DOMINGUEZ, ESTEPA \& CUENCA, 1999, p. 27-28) .

Régis Ramos afirma que toda exposição é uma violência topográfica, uma vez que a prática comum aos museus é espetacularizar o objeto, extirpan- 
do seu valor de uso sem considerar a sua outra posição, ou seja, sua historicidade. Cada objeto apresenta uma experiência vivida na relação com os homens, uma vez que eles próprios podem ser extensões do corpo. Mas a operação museológica rouba pedaços do mundo, prende-os nas vitrines e deixa-os morrer, para prometer-lhes vida eterna nos templos do chamado patrimônio histórico. (RAMOS, 2004, p. I37).

Em uma proposta educativa, Régis Ramos sugere que as operações museológicas sejam reveladas a estudantes e professores, pois é importante que saibam os caminhos percorridos pelo objeto até as galerias do museu e quais as estratégias discursivas estão propostas em suas exposições, seja de caráter permanente ou temporário. É fundamental que seja revelada a esses visitantes, em especial, a história do prédio que abriga o museu e a história da constituição de seu acervo.

Os museus têm como desafio o estabelecimento de um diálogo profícuo com a escola no sentido de estimular experiências significativas para professores e estudantes, relacionando os tempos de pré-visita, visita e pós-visita e com articulações entre as demandas docentes e os projetos educativos dos museus. Muitos caem na lógica produtiva, ou seja, atender ao maior número de escolas em menor tempo, o que garante maior público e mais recursos. Entretanto, muitas vezes não conseguem manter um quadro permanente de educadores e a rotatividade da equipe acaba prejudicando os diálogos que poderiam ser estabelecidos com professores, para além do tempo episódico da visita. A permanência também permitiria consolidar quadros formativos no próprio museu, com amadurecimento de seu projeto educativo, evitando retrabalho de formação e retorno à estaca zero em termos de preparação para o trabalho de recepção de públicos escolares.

O episódio da visita pode ser potencializado com ações articuladas vislumbrando espaços de troca de experiência entre educadores no museu e na escola, afirmando a necessidade de adensamento desta relação com superação do modelo de primeira e única visita, sem vínculos e sem negociações para idealização do projeto de visitação.

É preciso ressaltar que as visitas guiadas sem o planejamento do professor não constituem uma metodologia apropriada para estimular a capacidade cognitiva. Se recorrermos a nossa memória e alcançarmos a visão do monitor que guia um grupo de crianças no espaço do museu em um tempo determinado e, em virtude deste mesmo tempo, passa de forma rápida pelos objetos explanando sobre sua historicidade, veremos que estamos longe de sistematizar um método coerente para um trabalho de educação patrimonial nos museus.

De acordo com Júnia Sales, para que o professor possa usar o museu de forma significativa ele deve partir do entendimento que este espaço possui múltiplas linguagens e, assim, o tempo de aprender exige outra cadência, outros compassos e outros ritmos (PEREIRA, 2007).

Podemos supor que, ao declarar oferecer visita guiada estará o museu, necessariamente, tornando evidentes concepções reflexivas acerca da relação museu-escola? Sabemos o quanto algumas instituições - museus e escolas - estão distantes do que se considera significativo para valorização de experiências no processo educativo. A visita guiada pode ser momento rico de enunciação da relação dos estudantes e professores com a cultura e com os vestígios do museu e também com a sua proposta expositiva. Mas pode ser momento de referendum de discursos unívocos e postos como definitivos, sem inquirições.

Como afirma Junia Sales Pereira, o museu, além de um espaço de aprendizagem, é também local de encantamento, entretenimento e admiração (PEREI- 
RA, 2007, p. I I). É necessário que no tempo da visita seja permitido que o estudante se relacione com o acervo. A experiência com a exposição é momento de aprendizagem estética, pressuposto de uma educação sensível.

A criação de programas de atendimento especializado aos docentes em setores educativos dos museus pode favorecer não somente a que os professores se qualifiquem para esta relação e usufruto educativo, mas que os museus, como instituições mutáveis, também possam mapear as expectativas e impressões dos professores, alterando seus projetos de recepção de públicos escolares. Chamamos de atendimento especializado aos serviços, atividades e programas permanentes criados no museu que favorecem vínculos mais efetivos com a sociedade e dos professores com os museus, com alteração de hábitos culturais e amadurecimento de propostas de visitação escolar.

Com a criação desses programas, o fazer educativo nos museus passa a ser visto como oportunidade formativa, uma vez que é rico em experiências, contatos e trocas. Professores e educadores de museus aprendem com a prática e experiência que são reavaliadas e reposicionadas no processo educativo. Assim, atividades nos museus que são desenvolvidas com os professores podem contribuir para novas experiências educativas com os estudantes nas escolas. A atividade docente é antes de tudo baseada em interações entre seres humanos: dos professores com os estudantes, seus colegas de profissão e, também, com as equipes educativas dos museus (SALES \& SIMAN, 2009, p. 4).

\section{O Museu nos expõe}

Os museus propõem uma narrativa que pode nos encantar e desencantar, causar conforto e horror, isso porque o museu também nos expõe. $O$ museu revela o nosso lado humano e proporciona experiências das quais nos apropriamos para usá-las em nossa vida cotidiana. Em uma visita, seja de caráter educativo ou lazer, nos expomos ao museu. Hilde Hain propõe pensar o museu como uma avenida que nos conduz para fora de nós mesmos, ao mesmo tempo em que nos faz voltar para nossa mais íntima realidade (HAIN apud SOARES, 2008, p. 42).

A exposição em um museu relaciona o visível e o invisível, o material e o imaterial, pois como afirmou Merleau-Ponty (1999) a imagens que se apresentam ao mundo não passam de fantasmas do real, são a pré-coisa, e nosso corpo detentor de nossa percepção, destrói a ilusão de que vemos integralmente as coisas. $O$ que vemos é até onde nosso corpo permite ver, ou seja, uma face do universo perceptual. Nesse ambiente de dispersões estão também envolvidos nossos outros sentidos que nos permite sentir, imaginar, ouvir, arrepiar, encantar, indignar-se, etc.

Dessa problemática é preciso entender que o museu opera a partir da dialética entre o visível e o invisível, o tangível e o intangível, e nesse sentido encarna nossa experiência sensível e o sujeito visitante também encarna o museu, no sentido de que o sentimos em nosso corpo. Ao mesmo tempo o museu nos encarna porque por ele atravessamos, constituímos itinerários, rememoramos, comentamos ou simplesmente silenciamos. A experiência é essencialmente imaterial, enquanto a visão, como o olfato e o paladar, faz parte dos sentidos humanos. É preciso assim entender que somos atravessados pela exposição do museu.

No museu os visitantes são sujeitos andarilhos que percorrem um trajeto em relação com objetos, cenários, espaços vazios e com outros sujeitos no museu. $O$ museu convida a percorrer esse trajeto, por isso Pereira (2007) 
acredita que os visitantes são andarilhos que trilham o museu em sua busca por conhecimento ou outras mediações possíveis com a exposição. Usaremos o termo da autora para entender de que forma esse sujeito pode ser abordado nas práticas educativas dentro e fora dos museus, principalmente a partir de uma chave fenomenológica.

Os sujeitos andarilhos nos museus usam em primeiro lugar o corpo e com ele subverte a lógica imposta pela exposição. No seu trajeto pelo museu os sujeitos andarilhos observam por um tempo maior um objeto, passam por outros, leem as plaquetas que acompanham os objetos, partilham com outros sujeitos impressões em sua trajetória nas galerias e, às vezes, ignoram a explicação dos educadores. Enfim, a experiência de uma visita ao museu é antes de tudo humana. Para Soares e Scheinner (2010) a experiência nos museus (...) consiste numa relação do humano com o real que reflete sobre o próprio individuo, que passa a se ver em relação às coisas que o cercam no mundo (SOARES \& SCHEINNER, 20 I0, p. I5).

A dinâmica corporal permite que sejam construídas relações com os objetos, posto que, ao nos movermos, fechamos em uma visão melhor da sua forma (gestalt). Merleau-Ponty (1999) afirma que o corpo relaciona-se com nossas expressões uma vez que:

\section{(...) nele a experiência visual e a experiência auditiva, por exem- plo, são pregnantes uma da outra, e seu valor expressivo funda a unidade antedepredicativa do mundo percebido e, através dela, a expressão verbal (Darstellung) e a significação intelectual (Bedeu- tung). Meu corpo é a textura comum de todos os objetos e é, pelo menos em relação ao mundo percebido, o instrumento geral da minha compreensão (MERLEAU-PONTY, 1999, p. 315)}

O corpo é um meio de comunicação com o mundo e, portanto, nossa percepção é em um primeiro momento física e subjetiva. No museu são as coisas que se apresentam para a percepção. Para Merleau-Ponty (2009) a centralidade do corpo se expressa por (...) todo seu arranjo interno, por seus circuitos sensoriais-motores, pelas vias de retorno que controlam e relançam os movimentos, ele se prepara, por assim dizer, para uma percepção de si, mesmo se nunca é ele que ele próprio percebe ou ele quem o percebe. (MERLEAU-PONTY, 1999, p. 21)

O museu se constrói como fenômeno humano, pois nessa morada de dispersões há o encontro do ser com a própria coisa. E a tentativa de compreensão das coisas no mundo e os modos de nele estar não se faz por meio de uma percepção passiva, mas resulta do esforço do ser em sua presença (MERLEAU-PONTY, I999, p. 94). E há também o encontro do ser com outros seres, pois como em nossa presença no mundo estamos abertos a outros seres a partir de nossos reflexos, sensações e percepções.

Como uma morada de fragmentos o museu é um cenário de deslocamentos. Os sujeitos percorrem a narrativa organizada pelos projetos curatoriais e propõem outras, muito menos universais e objetivas, que fazem parte de sua memória individual. $E$ talvez resida aí o principal desafio às equipes educativas dos museus, ou seja, trabalhar com essa diversidade de experiências sociais e culturais para promover uma educação sensível, ética e estética.

\section{Museu e educação dos sentidos}

A sensibilidade é provocada por informações exteriores ao corpo no momento em que o homem é lançado ao mundo constituído por cores, odores, gostos, 
formas e ativamente interpretamos essas qualidades e usamos em nossas ações cotidianas (MERLEAU-PONTY, 1999). Nossa relação com as coisas se dá com base nos saberes sensíveis, no conhecimento tácito, na nossa capacidade de perceber as sensações, designada pelos gregos pela palavra Aisthesis. A sensibilidade é:

uma categoria do conhecimento e uma categoria política. Ela é a
base, a via de acesso ao mundo externo ao nosso corpo, o modo
como se estabelece nossa relação com as coisas, justamente por
ser um modo como experimentamos nosso corpo e os demais
corpos. É o modo como olhamos para as coisas, como ouvimos,
mas também como as pensamos. (TIBURI, 2005)

A sensibilidade situa-se no campo da criatividade, da imaginação e da leitura poética que fazemos de nossas relações com as coisas e na partilha com outros homens em nosso universo relacional. No entanto, a ciência moderna, com sua base epistemológica e sua busca por neutralidade, afastou o inteligível do sensível.A educação, por sua vez, acompanhou o paradigma inaugurado com o iluminismo fundando um sistema que privilegiou a faculdade de pensar, sem admitir outras sensibilidades presentes na vida do homem. A educação escolar exigiu que o docente se tornasse um mediador entre estudantes e a razão. Assim, era necessário apartar esses estudantes dos saberes adquiridos na família e sociedade. Para Duarte Júnior (2000) essa concepção é tributária de uma sociedade industrial e contribui para formação de um sujeito fragmentado que caminha em uma vida profissional e um cotidiano sensível para o qual não tem nenhum preparo. $O$ saber dividido em disciplinas escolares afasta o sujeito da leveza que pode ser encontrada na vida cotidiana e reduz sua capacidade sensorial (DUARTE JÚNIOR, 2000, p. I7I).

As estratégias usadas na educação dos sujeitos levaram a uma especialização. Esse sujeito deixou de lado saberes diversos, especialmente aqueles ligados aos sentidos, em função de um conhecimento parcial da realidade vivida.A escola moderna foi base para introdução dos saberes constituídos pelas ciências articulados nos currículos e, em contrapartida, pela negação de todos os outros saberes adquiridos pelo conhecimento tácito.

$\mathrm{Na}$ contramão dessa concepção, a educação das sensibilidades é um processo de conferir atenção a nossos fenômenos estéticos, que reconheça o fundamento sensível da existência humana propiciando seu desenvolvimento. Em uma educação sensível, o educador pode criar oportunidades de formação que ampliem a convivência, desenvolva a criticidade e a sensibilidade, de modo que o sensível e o inteligível se complementem. Segundo Duarte Junior (200l) é necessário reassumir os diversos saberes e sabores afastados da educação formal por um projeto de ciência cartesiana e investir na formação de um sujeito sensível, aberto às particularidades do mundo e todas as possibilidades de conhecimento disponíveis e dessa forma: estimular o sentimento de si mesmo e incentivar-se esse sentir-se humano de modo integral, numa ocorrência paralela aos processos intelectuais e reflexivos acerca de sua própria condição humana. (DUARTE JUNIOR, 2000, p I8I).

Os museus podem também se constituírem como ambientes formativos para uma educação sensível, ética e estética, uma vez que essas instituições são espaços privilegiados para ver, ouvir, sentir e partilhar. São também ambientes de pertencimento, nos quais forjamos nossa identidade e nos abrimos a novas experiências.

As visitas de estudantes às exposições dos museus podem proporcionar um aprendizado que torne possível a experiência que os levam a atos reflexivos em detrimento de atitudes contemplativas. Nas visitas a esses ambientes forma- 
tivos acionamos a visão, audição, tato, olfato, e por que não, a degustação. Como vadios, adentramos os museus e sentimos horror, medo, espanto, indignação, encantamento, ou até mesmo nos aborrecemos com a visita. Portanto, não se trata de dotar as exposições de aparatos interativos que muitas vezes anestesiam os sentidos, mas sim entender as vadiagens que ocorrem nos museus, uma vez que é no plano afetivo que a mente e o corpo se mobilizam em conjunto, "abrindo os espaços do mental para novos saberes, novas visões de mundo, novas experiências, novas possibilidades de percepção. (SCHEINER, 2003, p. 2)

Há desafios colocados aos professores e setores educativos dos museus no que se refere particularmente ao ensino de história. Um primeiro deles é a formação de parcerias com as escolas no sentido de romper com uma visão de museu contemplativa e ilustrativa, na qual o educador do setor educativo conduzirá as turmas de estudantes para complementar o saber curricular, confrontado o abstrato com o concreto. Os setores educativos podem, também, convocar os professores para suas ações que extrapolem os cursos de formação para uso dos museus, além de reconhecerem que as exposições não encerram uma finalidade educativa, que se prolonga no pré e no pós-visita em atividades na escola.

Um segundo desafio refere-se à própria lógica racional na qual o museu se organiza. Para Scheiner (2003) só existe ordem no mundo para quem nunca se dispôs a ver. Assim, as visitas aos museus não podem prescindir de um momento livre, no qual os estudantes poderão se relacionar com os objetos e perceberem as dimensões invisíveis da experiência que se dá para além do domínio da matéria. Se muito preso à lógica racional da escola, educadores de museu e professores acabam tolhendo aquilo que pode ser mais significativo na visita: o conhecimento que parte da informação e é elaborado pela emoção transformando-se em vivência (SCHEINER, 2003, p. 3). Essa atitude rompe com uma lógica transmissiva e propõe atos mais reflexivos aos estudantes nos museus.

O terceiro desafio relaciona-se à angustia pela visita total. Ainda que o tempo disponível seja adequado, ele deve ser dividido entre a proposição de uma reflexão no acervo e de um tempo livre para os estudantes, o que pode ser feito simultaneamente durante o tempo da visita.Assim, torna-se impossível ver todo acervo do museu, percorrer todas as suas salas. A exposição é, também, uma seleção porque enunciam histórias, mas também nos impedem de perceber as múltiplas articulações temporais e corpóreas da vida (PEREIRA \& CARVALHO, 20 I0, p. 390). Portanto, os professores não devem se angustiar na tentativa de ver todo o museu. Torna-se mais significativo selecionar trajetos no museu que potencializem as discussões feitas na pré-visita.

O que Ulpiano Bezerra Menezes (2005) chamou de alfabetização museológica, sem dúvida, configura-se como um quarto desafio. Muitas vezes não estão acessíveis aos estudantes as formas como a exposição foi construída, quais profissionais envolvidos, a origem da coleção e que outras possibilidades narrativas são possíveis a partir do acervo. A história do prédio que abriga a coleção é, também, uma das informações que nem sempre são disponibilizadas no ato da visita. A alfabetização museológica seria, portanto, discutir de que forma a exposição foi construída, quais objetos selecionados e quais as origens do acervo e dados mais precisos sobre o discurso pretendido pela curadoria para além dos tradicionais catálogos.

As exposições atuais aproximam-se muito do espetáculo, com soluções advindas das novas mídias, como "leads", e outros aparatos interativos. Para Scheiner (2003) é um grande equívoco pensar que essas soluções atingem ple- 
namente o visitante ou proporcionam-lhes maior interação. $\mathrm{Na}$ verdade esses aparatos acabam por supervalorizar algumas memórias em detrimento de outras e promovem uma redução interpretativa. Os museus devem se atentar para:

(...) estratégias narrativas integrando passado e presente, e buscando apresentar os fatos a partir de uma ótica plural, que permita $\circ$ máximo possível de interpretações. $\bigcirc$ compromisso com o rigor histórico e científico deve aliar-se ao uso equilibrado do design, buscando o desenvolvimento de soluções museográficas que sejam criativas e que não comprometam o papel ético do museu. Isto implica também no uso equilibrado dos recursos cenográficos, de multimídia e da dramatização, que deverão trabalhar a emoção dos visitantes, sem deixar-se cair no exagero ou no pieguismo. (SCHEINER, 2003, p. 4)

Nessa consideração de Scheiner é possível refletir sobre um quinto desafio a professores e equipes educativas dos museus quanto ao ensino de história. A articulação entre o passado e presente e a criação de utopias a partir da inclusão na exposição de objetos produzidos na atualidade é um dos caminhos para romper com a visão tradicionalmente atribuída aos museus. Para Régis Ramos (2008) o ato de pensar sobre o presente vivido está relacionado com as formas de conhecer o passado, assim como conhecer o presente está referenciado no pretérito. Nesse sentido, cabe refletir sobre o presente como algo que não era e que pode ser diferente, identificando outras possibilidades para vida em sociedade. O sentido do conhecimento histórico é o de revelar outras possibilidades, renovar expectativas e reinventar novas formas de vida em comum rompendo com a ideia de que é assim porque sempre foi assim (RAMOS, 2004, p. 21 ).

Refletir sobre esses desafios é um dos caminhos para que a relação entre setores educativos e professores torne-se cada vez mais estreita e os projetos de uso dos museus pelos estudantes possam objetivar uma formação ética e estética. Essa relação é de partilha e não de autoridade de um sobre o outro. Para Ranciére (2005) a partilha do sensível possibilita os deslocamentos, identificação e diferenciação, em um processo de troca entre o "eu” e o "outro". A partilha do sensível evidencia o "comum" e os recortes definidos de lugares e perspectivas, fixando um "comum" partilhado e partes exclusivas que (...) se funda numa partilha de espaços, tempos e tipos de atividades que determina propriamente a maneira como um "comum" se presta a participação e como uns e outros tomam parte nessa partilha (RANCIÉRE, 2005, p. I5).

Cabe, então, promover essa partilha criando projetos comuns entre museu e escola, que tomem como ponto de partida a especificidade dessas duas instituições. Os momentos que antecedem e os posteriores à visita devem ser também incluídos nessa partilha, no rompimento da visão da visita ao museu como uma finalidade no processo educativo.

\section{O Programa Nacional de Educação Museal}

No ano de 2010 foi realizado na cidade de Petrópolis o I Encontro de Educadores do IBRAM, órgão de criação recente que propõe diretrizes para a política museal no Brasil e gere museus ligados ao governo federal. Esse encontro tinha como objetivo principal traçar diretrizes para a elaboração de uma politica pública de educação museal e refletir sobre as experiências de ações educativas em curso nos museus brasileiros. A dinâmica do evento se deu por meio de grupos de trabalho que se reuniram e sintetizaram as propostas em uma carta de intenções conhecida como Carta de Petropólis. 
Os grupos utilizaram como base, além de referenciais teóricos e metodológicos, a Lei I I904/2009 que instituiu o Estatuto dos Museus em que no artigo 29 define que:

Os museus deverão promover ações educativas, fundamentadas no respeito a diversidade cultural e na participação comunitária, contribuindo para ampliar o acesso da sociedade às manifestações culturais e ao patrimônio material e imaterial da Nação.

A promoção da diversidade e diálogo com a comunidade aliada a democratização de acesso aos bens culturais é um desafio antigo para as instituições museais que não está atrelado apenas a ações educativas para as escolas. Os museus devem encarar a educação em um sentido amplo como acesso universal aos bens culturais para emancipação do homem.

A Carta de Petrópolis apresentou como propostas que ações educativas devem estar inseridas no plano museológico, bem como na missão das instituições. Apontou também a importância de um diálogo teórico considerando o campo da museologia e da educação. De fato é recente o interesse da museologia pelas ações educativas que se inserem nos museus. Até bem pouco tempo, esse campo do conhecimento não via a educação como uma das ações primordiais do museu.A inserção de pesquisadores da educação em museus em bases epistemológicas da museologia contribui para ampliação da bibliografia da área que não é rara, porém está ainda por ser reunida.

Em outubro de 2012, com as discussões feitas em Petropólis o IBRAM lançou o Blog do PNEM, uma ferramenta virtual para ampliar as discussões que levariam a elaboração de um Programa. Como metodologia, foram propostos 9 eixos para discussão: Perspectivas conceituais; Gestão; Profissionais de Educação Museal; Formação, capacitação e qualificação; Redes e parcerias; Estudos e pesquisas;Acessibilidade; Sustentabilidade; e Museus e Comunidade.

\section{Figura 0I-Apresentação da metodologia do PNEM}

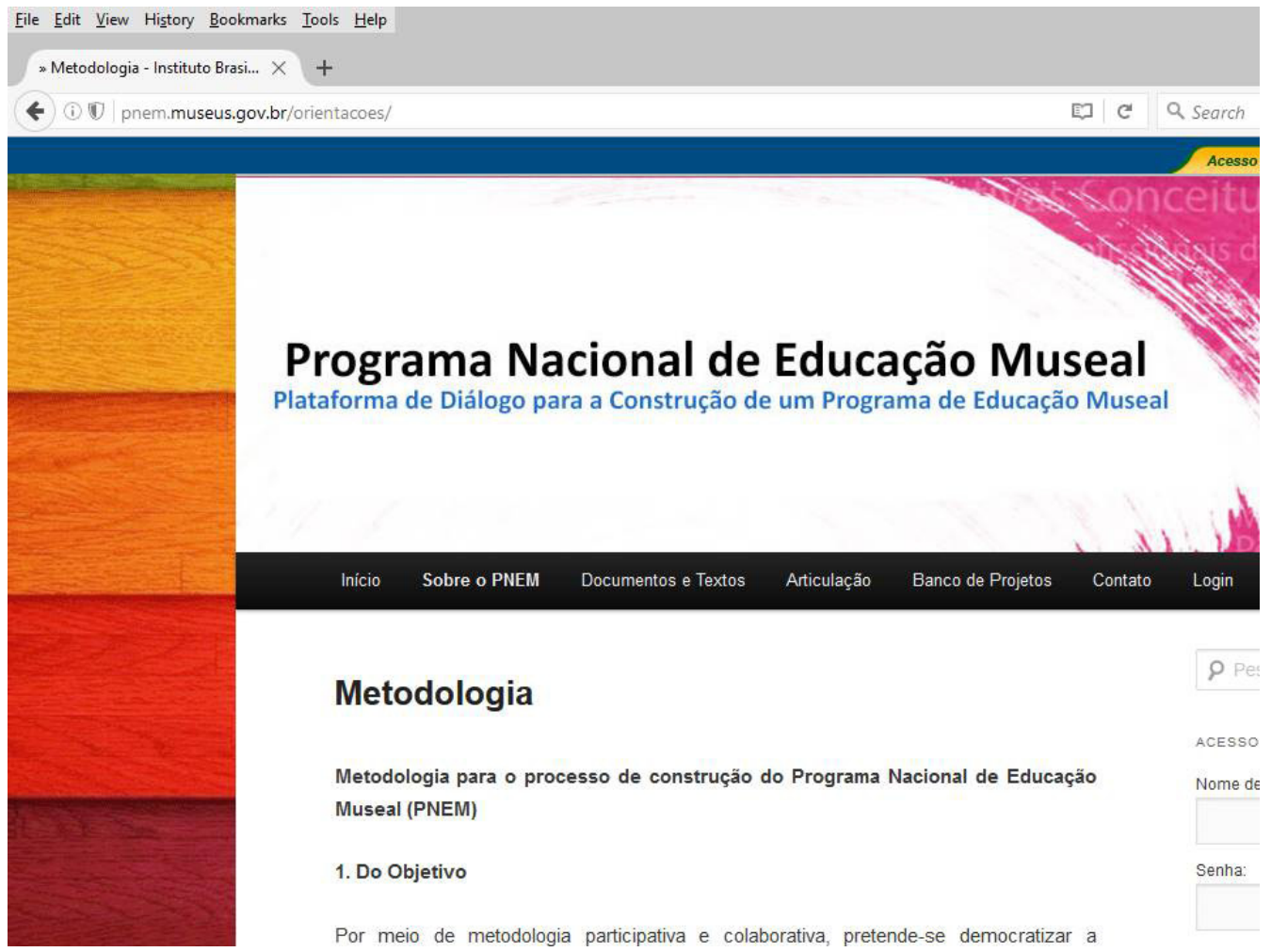

Fonte: PNEM (http://pnem.museus.gov.br/) 
O instrumento disponilizado nas redes sociais fomentou debates de extrema importância para o campo da educação museal a partir das articulações propostas pelos coordenadores dos GT's conforme a tabela abaixo:

\section{Tabela 0 I}

\begin{tabular}{|l|l|l|}
\hline GT & Tópicos & Postagens \\
\hline Perspectivas Conceituais & 15 & 129 \\
\hline Gestão & 6 & 67 \\
\hline $\begin{array}{l}\text { Profissionais de Educação } \\
\text { Museal }\end{array}$ & 11 & 143 \\
\hline $\begin{array}{l}\text { Formação, capacitação e qua- } \\
\text { lificação }\end{array}$ & 8 & 65 \\
\hline Redes e parcerias & 8 & 58 \\
\hline Estudos e pesquisas & 8 & 48 \\
\hline Acessibilidade & 7 & 45 \\
\hline Sustentabilidade & 9 & 41 \\
\hline Museus e Comunidades & 11 & 85 \\
\hline
\end{tabular}

Fonte: PNEM (http://pnem.museus.gov.br/)

Estes nove eixos transformaram-se em fóruns de discussão via web sendo que o que obteve o maior número de participações foi o de Profissionais da Educação Museal. Nestes fóruns era possível os participantes postarem tópicos diversos e os articuladores seriam os responsáveis por reunir as principais propostas. Os fóruns foram coordenados por articuladores definidos entre os funcionários do IBRAM.

O fórum de Perspectivas Conceituais teve 15 tópicos e 129 participações conforme podemos observar na figura abaixo.

\section{Figura 02- Fórum do PNEM}

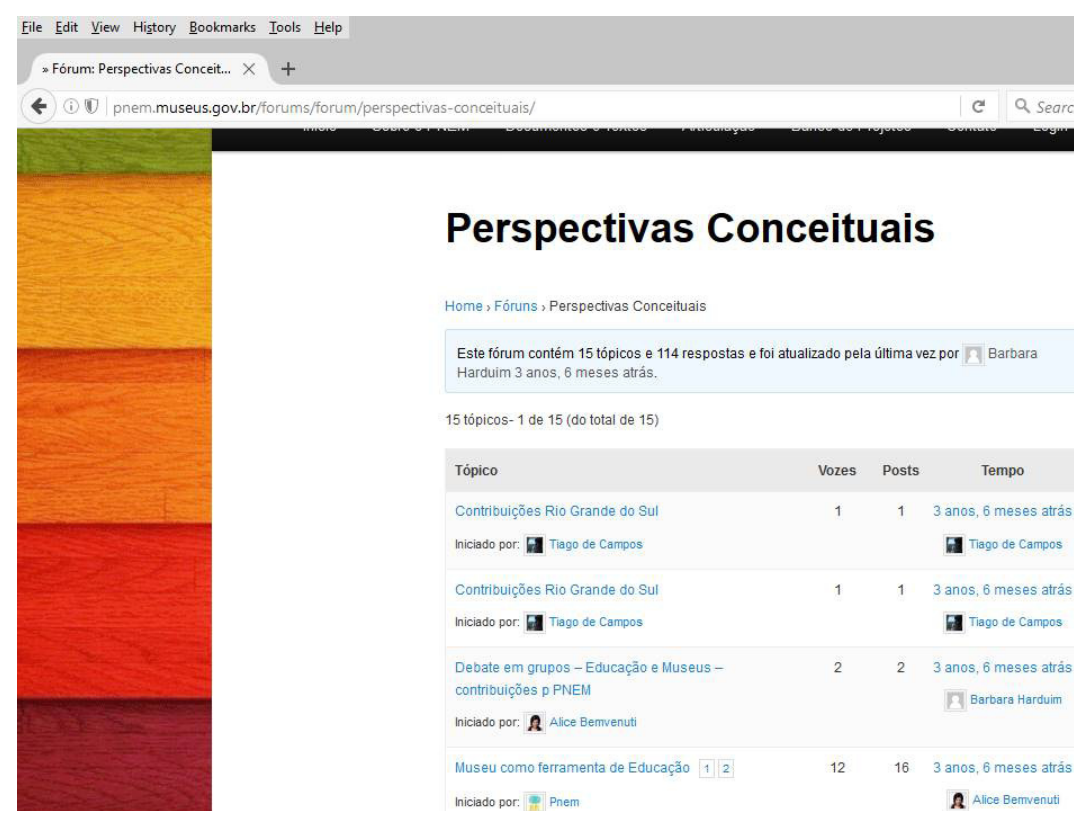

Fonte: PNEM (http://pnem.museus.gov.br/) 
No post Museus como Ferramenta de Educação o administrador propôs a seguinte reflexão: assegurar que os museus e espaços de memória sejam importantes ferramentas de educação, e que por meio de ações transversais colaborem para o desenvolvimento cultural, social e econômico, regional e local; (http:// pnem.museus.gov.br/).

Um dos participantes do fórum estimulado por esse post questiona em que medida os museus são ferramentas para educação e de que tipo de educação seria promovida nesses espaços a partir de que projeto de sociedade. Como essa participação, o blog registrou mais 14 respostas. E dessa forma foram sendo efetivadas as outras discussões nos 9 fóruns propostos.

Foge ao escopo desse artigo analisar todas as vozes que deram subsidio para elaboração do Documento Preliminar no PNEM. Esse exemplo foi apenas para ilustrar como foi feita a elaboração do documento debatido em Belém durante a realização do $6^{\circ}$ Fórum Nacional de Museus em 2014. Naquele encontro foram apresentados os dados coletados nos fóruns virtuais que contou com 708 pessoas cadastradas e 55 articuladores. Também foram feitos 23 encontros regionais em 13 unidades da federação que reuniu cerca de 650 pessoas.

A plenária final resultou em um documento intitulado Carta de Belém que apresenta princípios para a formulação de uma política de educação museal que serviria como diretriz para elaboração posterior de uma minuta. $O$ próximo encontro do PNEM ficou previsto para o segundo semestre de 2015, mas infelizmente não foi realizado devido a falta de investimento do Ministério da Cultura nesse programa setorial do IBRAM. ${ }^{3}$

\section{Considerações Finais}

A elaboração da Política Nacional de Museus em 2003 e a posterior criação do IBRAM em 2009 atendendo a lutas antigas dos profissionais dos museus abriram a possibilidade de pensar em programas voltados especificamente para educação museal. O PNEM veio como consequência das discussões iniciadas nos Fóruns Nacionais de Museus, evento bienal que reúne profissionais da área para pensar ações voltadas para os museus no país. No primeiro fórum acontecido em Salvador os GT's discutiram as ações educativas e foi ofertado um minicurso de educação em museus. ${ }^{4}$ Existem ainda muitos desafios para implementação da política, mas a difusão do termo "educação museal", concursos para pesquisadores com foco na educação em cursos de museologia e para técnicos na área no IBRAM, grupos de estudos, teses e dissertações é um sintoma de que a discussão se frutifica e ganha contornos cada vez mais práticos.

Os museus são ambientes formativos que podem promover a troca de experiências entre docentes e equipes educativas, oportunizando programas e projetos articulados às práticas desenvolvidas na escola e no museu, respeitando a peculiaridades de cada instituição. Está posto a essas instituições o desafio de criar projetos de visitação articulados com os professores, respeitando as demandas apresentadas por esses profissionais a partir de suas experiências como docentes. Assim, os setores educativos dos museus poderão aproveitar das experiências docentes para melhoria de suas propostas educativas com os acervos na visita de estudantes. Ao mesmo tempo, os professores redimensio-

${ }^{3} \mathrm{O} 7^{\circ}$ Fórum Nacional de Museus seria realizado em Porto Alegre em 2016. O evento foi suspenso por falta de verbas.

${ }^{4}$ No segundo Fórum realizado em Ouro Preto, a professora Magaly Cabral (diretora do Museu Da República) ofertou um minicurso de ações educativas em museus. A discussão ganhava mais peso entre os profissionais da museologia. 
nam sua prática tendo o museu como possibilidade para promover uma educação para as sensibilidades éticas e estéticas.

Com essa proposta, os museus podem tornar-se ambientes nos quais os docentes reavaliam suas práticas, reposicionam suas formas de ver e entender 0 mundo e encontram outros caminhos possíveis para uma leitura da sociedade. As experiências dos docentes interessam às equipes educativas dos museus, uma vez que a educação se dá em uma perspectiva dialógica, e essa abertura pode melhorar os projetos desenvolvidos em programas permanentes que consolidem a relação com as escolas e comunidade.

Pensamos nessa relação dialógica a partir da circularidade cultural, em que esses sujeitos trocam impressões sobre a memória cultural, os usos do passado, sobre a memória e o esquecimento e formas de trilhar outros caminhos na formação dos estudantes nos museus. Cada um com sua história de vida, todos são portadores de experiências que podem contribuir para um redimensionamento da relação museu-escola, fugindo, assim, de uma relação pragmática em que o museu é visto como ilustração de conteúdos. E da parte do museu, a visita de escolares passa a ser vista como justificativa social para a sua existência.

\section{Referências}

BITTENCOURT, José Neves. Québec acabou? Para os próximos 20 anos. In: CHAGAS, Mário et all. A democratização da memória: a função social dos museus ibero-americanos. Rio de Janeiro: Museu Histórico Nacional, 2008.

BREFE, Ana Claudia F. Os primórdios do Museu: Da elaboração conceitual à instituição pública. Projeto História I7.Trabalhos da Memória. São Paulo, Novembro de 1998.

CHAGAS, Mário \& STORINO, Claudia M. P.Apresentação. Revista Musas. Rio de Janeiro, n 3, p 6-8, 2007.

DOMINGUEZ, C. ESTEPA.J.\& CUENCA.J.M. El museo. Un espacio para el aprendizaje. Universidad de Huelva, Huelva, 1999.

DUARTE JÚNIOR, João Francisco. $\mathbf{O}$ sentido dos sentidos. A educação (do) sensível. Tese de doutorado. Campinas. Faculdade de Educação da Unicamp. 2000.

IBRAM, Programa Nacional de Educação Museal. http://pnem.museus.gov.br/ acesso em 06/09/2016

LOPES, Margaret Maria.A favor da desescolarização dos museus. Revista Educação Sociedade, Campinas, v.3, n. 40, dez., 1991.

MACHADO, Roberto. Nietzsche e o renascimento do trágico. Kriterion. Belo Horizonte, $\mathrm{n}^{\circ}$ I I2, p. I74-I82, Dez/2005.

MENEZES, Ulpiano Bezerra. A exposição museológica e o conhecimento histórico. In: FIGUEIREDO, Betânia Gonçalves \& VIDAL, Diana Gonçalves. Museus. Dos gabinetes de curiosidades à museologia moderna. Belo Horizonte: Argumentum, 2005.

MERLEAU-PONTY, Maurice. Fenomenologia da Percepção. São Paulo: Martins Fontes, 1999.

PEREIRA, Junia Sales \& CARVALHO, Marcus Vinicius Corrêa. Sentidos dos tempos na relação museu/escola. Cadernos Cedes. Campinas, Vol. 30, n. 82, p. 383396, set.-dez. 2010. 
PEREIRA, Junia Sales. Educadores de museus e seus processos formativos. Palestra projeto Museu e Escola. Cefor/PUC-Minas e LEME/UFMG.2007

PEREIRA, Junia Sales; SIMAN, L. M. C. Educadores em zonas de fronteira - Limiares da relação museu-escola. In: NASCIMENTO, Silvania Souza; FERRETI, Carla Santiago. (Org.). Museu e Escola. Anais. Belo Horizonte: Puc Minas/UFMG, 2009, v. I, p. I-I5.CD.

POULOT, Dominique. O modelo republicano de museu e sua tradição. In: BORGES, Maria Eliza Linhares (org) Inovações, Coleções, Museus. Belo Horizonte:Autêntica, 20II.

RAMOS, Francisco Régis Lopes. A danação do objeto: o museu no ensino de História. Chapecó:Argos, 2004.

RANCIÈRE, Jacques. A partilha do sensível. Estética e Política. São Paulo: Editora 34, 2005.

SCHEINER, Tereza Cristina. O museu como processo. Cadernos de Diretrizes Museologicas 2: mediação em museu: curadorias, exposições, ação educativa. Belo Horizonte: Secretaria de Estado da Cultura de Minas Gerais, Superintendência de Museus, 2008.

Comunicação, educação, exposição: novos saberes, novos sentidos. Semiosfera. Revista de Comunicação e Cultura.Ano 3. N 4-5, julho de 2003.

\& SOARES, Bruno.A chama interna: museu e patrimônio na diversidade e na identificação. Museologia e Patrimônio. Revista Eletrônica do Programa de Pós-Graduação em Museologia e Patrimônio. V. 3, n.I, jan/jun de 2010 .

Repensando o museu integral: do conceito às práticas. Boletim do Museu Paraense Emilio Goeldi. Belém, v. 7, n. I, p I530, jan/abr de 2012.

SOARES, Bruno C. Brulon. Quando o museu abre portas e janelas. $O$ reencontro com o humano no museu contemporâneo. Dissertação de mestrado. Rio de Janeiro. UNIRIO, MAST, 2008.

SUANO, Marlene. O que é museu. São Paulo: Brasiliense, 1986.

TIBURI, Márcia. O que é sensibilidade? Disponível em:

www.artenaescola.org.br/pesquise artigos texto.php?id m=29

Artigo recebido em janeiro de 20 I7.Aprovado em julho de 2017. 